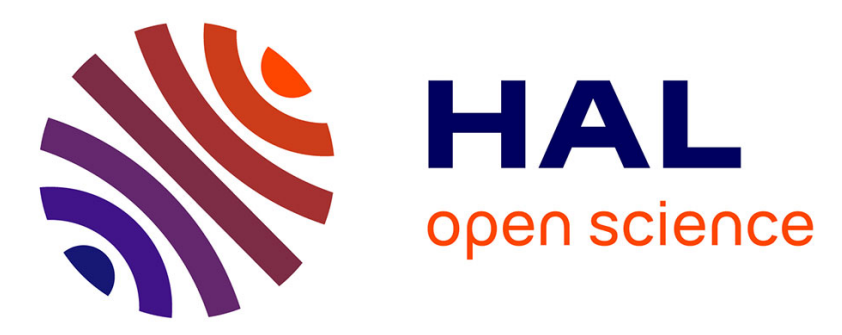

\title{
Experimental Study of the Impact of Substrate Shape and Tilting on Particle Velocity in Suspension Plasma Spraying
}

Alice Dolmaire, Simon Goutier, Aurélien Joulia, Pierre-Marie Geffroy, Michel Vardelle, Luc Bianchi

\section{To cite this version:}

Alice Dolmaire, Simon Goutier, Aurélien Joulia, Pierre-Marie Geffroy, Michel Vardelle, et al.. Experimental Study of the Impact of Substrate Shape and Tilting on Particle Velocity in Suspension Plasma Spraying. Journal of Thermal Spray Technology, 2020. hal-02453433

\section{HAL Id: hal-02453433 \\ https://hal-unilim.archives-ouvertes.fr/hal-02453433}

Submitted on 11 Dec 2020

HAL is a multi-disciplinary open access archive for the deposit and dissemination of scientific research documents, whether they are published or not. The documents may come from teaching and research institutions in France or abroad, or from public or private research centers.
L'archive ouverte pluridisciplinaire HAL, est destinée au dépôt et à la diffusion de documents scientifiques de niveau recherche, publiés ou non, émanant des établissements d'enseignement et de recherche français ou étrangers, des laboratoires publics ou privés. 
Experimental study of the impact of substrate shape and tilting on particle velocity in Suspension Plasma Spraying

\author{
A.DOLMAIRE ${ }^{1,2}$, S.GOUTIER ${ }^{1}$, A.JOULIA ${ }^{2}$, P-M.GEFFROY ${ }^{1}$, M.VARDELLE ${ }^{1}$, \\ L.BIANCHI ${ }^{3}$ \\ ${ }^{1}$ Univ. Limoges, CNRS, IRCER, UMR 7315, F-87000 Limoges, France \\ ${ }^{2}$ Safran Tech, Rue des Jeunes Bois, 78772 Magny Les Hameaux, France \\ ${ }^{3}$ Safran Aircraft Engines, 1 Rue Maryse Bastié, 86100 Châtellerault
}

\begin{abstract}
\end{abstract}
Suspension plasma spraying has shown its capacity to deposit finely structured coatings with a wide range of microstructures including columnar microstructures that are generally sought in thermal barrier coating applications for gas turbines. However, some challenges are still to be taken up before the application of the technology at an industrial scale. One deals with the deposition of a uniform and reliable coating on a complex shape substrate. This work offers an experimental observation of submicron particle streams close to the substrate in order to understand mechanisms of deposition. Effects of the substrate shape and tilting were investigated on particle velocity, directions and coating growth. It was shown that particle velocities and directions are disrupted by the substrate presence up to $10 \mathrm{~mm}$ upstream. When the substrate is a cylinder or in a tilted orientation to the plasma jet, particles kinetic behaviour is less affected. Finally, submicron particle velocity vectors orientation near impact greatly shape the coating morphology. When impacting with a $40^{\circ}$ angle of incidence, columns appeared on beads, contrary to submicron particle streams impacting orthogonally to the substrate surface. 
1 Keywords particle velocity, suspension plasma spraying, thermal barrier coating, columnar

2 coating, substrate shape, substrate orientation, PIV

\section{Introduction}

Suspension Plasma Spraying (SPS) is now emerging at the industrial scale, with most activities affecting new processes on the improvement of coatings on gas turbines. In this context, coatings need to be homogeneously deposited along the surface of turbine blades to be truly effective. However, turbine blades are made of complex forms with a variety of thicknesses, curves and type of edges, which greatly influence the morphology and quality of the coatings obtained by SPS [1]. To improve deposition rate and quality, further investigations are needed to understand the behaviour of submicron particles flow in the plasma jet impinging the surface of substrates.

In Atmospheric Plasma Spraying (APS), particles launched at high speed have trajectories quasi parallel to the gun axis and almost all resulting impacts on the substrate are orthogonal to the target surface $[2,3]$. The kinematic treatment depends a lot on particle mean size $d_{p}$ which is in this case about more than $10 \mu \mathrm{m}[2,4,5]$.

However, in Suspension Plasma Spraying (SPS), submicron and nano-sized particle trajectories are greatly affected by flow fluctuations [6] and any velocity gradients [5,7]. Especially, near the target, these particles are very sensitive to the plasma flow directional change induced by the stagnation region [8], seemingly following plasma flow streamlines due to their very low Stokes number [9-12]. 
2 suspension of zirconia droplets within a plasma jet near a flat or curved surface. Their simulation has shown a significant influence of the substrate shape on particle trajectories in the vicinity of the substrate surface. Particles within a plasma jet impinging a cylindrical substrate were twice as likely not to deposit on the substrate surface. When impacting the cylinder, these particles also had a lower normal velocity (as regards the substrate normal axis) than particles impinging a flat substrate due to a narrower stagnation area.

Finally several models on coating growth in SPS have been suggested from experimental observations of coating morphologies obtained with varying sets of process parameters [14-18]. These models all agree on the great influence of particle direction and velocity when impacting the substrate on the resulting coating morphology. More precisely, the impacting directions of these particles on a peak of roughness seem to shape the coating into columnar morphologies via the shadowing effect.

Thus the presence of an obstacle totally disrupts the plasma and particle flow streams and affects their respective average velocity [19]. If submicron particles precisely follow plasma flow streamlines, as shown in simulations, how then is a SPS coating built when the centerline of the particle flow bearing a maximum of particles concentration rapidly decelerates and is easily deviated by the stagnation area?

No experimental investigation has yet been published, to the authors' knowledge, on the kinetic behaviour of suspension submicron particles in plasma jets impinging substrates. The objective of this study is therefore to provide it. Particle Image Velocimetry (PIV) will be used in order to observe submicron particles kinetic behaviour near two types of substrates, a flat substrate or a cylindrical one, with a tilted orientation or not to the plasma flow axis. Next the resulting coating morphologies will be analysed thanks to observations of cross-sections. 


\section{Experimental methods and set-up}

\section{Particle Image Velocimetry (PIV) principle and set-up}

PIV measurements consist in capturing movements of particles in a fluid thanks to an advanced optical set-up combined with a digital image correlation technique.

In this system (Fig. 1), two high-speed cameras were orthogonally placed to each other. The light is collected by the two cameras thanks to a beam-splitter. The lens of the first camera also determined the field of interest, i.e the spatial resolution. In this study the field was $12 \times 8 m^{2}$ and was $1 \mathrm{~mm}$ deep. A double-pulsed Nd:YAG laser (wavelength $\lambda=532 \mathrm{~nm}$ ) was used to radiate particles travelling through this field. The two cameras were then respectively synchronised to be exposed to only one pulse of the laser at a time in order to detect any movement in a couple of frames.

For this study, 100 image couples of dimensions $12 \times 8 \mathrm{~mm}^{2}$ and of exposure time $1 \mu \mathrm{s}$ were taken per operating condition. These conditions consisted in varying the substrate shape in front of the plasma jet as well as the tilting of the plasma gun in front of a flat substrate. The plasma gun working conditions were set constant during these sprayings. They are described in the next paragraph. Velocity fields were calculated from these 100 couples via an Eulerian approach thanks to the PIV software DaVis 8 (LaVision, Göttingen, Germany). Spatial auto-correlation was used to calculate the average pixel displacement of clouds of zirconia particles in an interrogation area of $128 \times 128$ pixels within a partial window of dimensions $3 \times 3 \mathrm{~mm}^{2}$. An overlap of $50 \%$ was applied between each interrogation area. These correlation parameters allows to obtain up to 9000 velocity vectors for 100 velocity fields of dimensions $3 \times 3 \mathrm{~mm}^{2}$. Arithmetic averages of magnitudes of these velocity vectors were then 
1 extracted from each windows of $3 \times 3 \mathrm{~mm}^{2}$. An average measurement error of $30 \mathrm{~m} \cdot \mathrm{s}^{-1}$ on

2 particle average velocity was estimated from the slight variations of substrates positioning

3 between and during spraying.

4

\section{Spraying conditions and beads production}

The ethanol-based suspension was homemade using an 8wt.\% yttria stabilized zirconia submicron powder $\left(\mathrm{d}_{50, \mathrm{v}}=0.7 \mu \mathrm{m}\right)$ from IMERYS Fused Minerals (Laufenburg, Germany) and $2 \mathrm{wt} . \%$ of phosphate ester as the dispersing agent (3DCeram, Limoges, France).

A TriplexPro-200 plasma gun from Oerlikon-Metco (Kelsterbach, Germany) was used to conduct the study. Spraying conditions are detailed in Table 1.

The suspension was then inserted in a pressurized tank with a magnetic agitation put underneath. It was later injected radially to the plasma jet at $4 \mathrm{~mm}$ from the nozzle exit. The injector diameter was $150 \mu \mathrm{m}$ and the suspension flowrate around $30 \mathrm{~mL} \cdot \mathrm{min}^{-1}$.

Two types of substrate were positioned at a standoff distance of 60mm (Fig. 2):

- A water-cooled circular copper plate, of diameter 50mm and thickness $28 \mathrm{~mm}$, put normal to the plasma flow in order to simulate a flat substrate (disk). It had a frontal area of $1964 \mathrm{~mm}^{2}$.

- Stainless steel rings, of diameter $50 \mathrm{~mm}$, height $32 \mathrm{~mm}$ and thickness $2 \mathrm{~mm}$, set vertically to behave as cylindrical substrates with a curvature radius of $25 \mathrm{~mm}$ and a frontal area of $1600 \mathrm{~mm}^{2}$.

In order to cool down substrate surfaces during each spray, standard TriplexPro commercial air-jets were used (details in Tab. 1). During PIV measurements, the cooled 
copper plate was set immobile while stainless steel rings were mounted vertically on a chuck rotating at 100rpm (Fig. 3).

Part of the study is dedicated to apprehending the influence of the substrate orientation on the submicron particle flow behaviour. Due to the limitations of the PIV set-up, it was of best interest to orient the plasma jet with respect to the normal axis of the substrate instead. Indeed, this configuration allowed to recreate a plasma flow impinging an inclined surface as well as to maintain the same measuring volume. Two orientations of plasma jet were chosen: parallel to the normal axis of the substrate $\left(0^{\circ}\right.$ of incidence) or impinging with a $40^{\circ}$ angle of incidence.

Next, this effect of the substrate orientation was studied by examining beads crosssections. These beads were sprayed on grit-blasted stainless steel rings while maintaining the plasma gun motionless. Their cross-section were observed thanks to a JEOL IT300LV (Jeol Europe, Croissy sur Seine, France) scanning electron microscope in order to characterize the plasma jet position effect on the obtained coating morphology. Porosity in the beads was also evaluated from the micrographs by image analysis using the open-source software ImageJ.

\section{Estimated plasma jet thermophysical properties in the vicinity of substrates}

In order to interpret velocity results, thermophysical properties of the plasma jet were necessary for an $80 \%-20 \%$ argon-helium gas mixture with atmospheric air surrounding it at $\mathrm{x}=60 \mathrm{~mm}$. Thus, the temperature, the viscosity and the density of the plasma flow were broadly estimated at $\mathrm{x}=60 \mathrm{~mm}$ as follow.

The plasma temperature $\mathrm{T}_{\text {plasma }}$ was first estimated by measuring the melting point position $\mathrm{T}_{\text {alumina }}$ of an alumina rod of diameter $3 \mathrm{~mm}$ in the plasma flow. The tip of the rod started to melt at $x=55.5 \mathrm{~mm}$ from the nozzle exit. Using previous work [20], values of the 
1 heat transfer coefficient $\mathrm{h}$ were considered to vary between 1500 and $3000 \mathrm{~W} \cdot \mathrm{m}^{-2} \cdot \mathrm{K}^{-1}$ and

2 thermal flux density $\Phi$ values in a range of 2 to $3 \mathrm{MW} \cdot \mathrm{m}^{-2}$ at $\mathrm{x}=60 \mathrm{~mm}$ from the gun nozzle exit. Thermal gradient in the boundary layer of the plasma flow could then be evaluated thanks to the following equation (Eq. 1).

$$
\Phi=\mathrm{h}\left(\mathrm{T}_{\text {plasma }}-\mathrm{T}_{\text {alumina }}\right) \quad(\text { Eq. } 1)
$$

Therefore, the plasma temperature $\mathrm{T}_{\text {plasma }}$ around $60 \mathrm{~mm}$ had been approximated to be roughly between 5150 and $5850 \mathrm{~K}$. In order to simplify further calculations, plasma temperature was set on the average value, which was $5500 \mathrm{~K}$. This value is close to previous SPS models with similar plasma conditions $[11,13]$. Thanks to this plasma temperature estimation, it was then possible to infer viscosity and density values for an argon-helium-air mixture at $\mathrm{x}=60 \mathrm{~mm}$. Volume fraction of air was set at $90 \%$ at this distance from the nozzle exit in the gas mixture [21]. Taking into account such air entrainment, plasma viscosity $\mu_{\mathrm{g}}$ was estimated to be around $1.6 \cdot 10^{-4} \mathrm{~kg} \cdot \mathrm{m}^{-1} \cdot \mathrm{s}^{-1}$ and density $\rho_{\mathrm{g}}$ around $5.4 \cdot 10^{-2} \mathrm{~kg} \cdot \mathrm{m}^{-3}$. These calculated properties will be taken into account for the following estimations.

Fluid dynamic of the plasma and particle flow in the vicinity of substrates

Reynolds number of the plasma jet and drag forces applied on the substrates can be estimated at $\mathrm{x}=60 \mathrm{~mm}$ thanks to the calculations in the previous paragraph. Submicron particles timely response to the plasma jet can also be gauged thanks to the Stokes number. These numbers and forces will help to better understand the dynamic behaviour of both flows (plasma and submicron particles) and thus will help into the interpretation of results on particle velocity.

Definitions of Reynolds number Re, drag force $F_{d}$ and Stokes number St are described subsequently. 


$$
\operatorname{Re}=\frac{\rho_{\mathrm{g}} \mathrm{v}_{\mathrm{g}} \mathrm{d}_{\mathrm{s}}}{\mu_{\mathrm{g}}}
$$

$$
\mathrm{F}_{\mathrm{d}}=\frac{1}{2} \rho_{\mathrm{g}} \mathrm{v}_{\mathrm{g}}^{2} \mathrm{~A} \mathrm{C}_{\mathrm{d}}
$$

$$
\mathrm{St}=\frac{1}{18} \frac{\rho_{\mathrm{p}} \mathrm{d}_{\mathrm{p}}^{2} \mathrm{vg}_{\mathrm{g}}}{\mu_{\mathrm{g}} \mathrm{D}}
$$

In the expression of the Reynolds number (Eq. 2), symbols $\rho_{\mathrm{g}}, \mathrm{v}_{\mathrm{g}}$, and $\mu_{\mathrm{g}}$ represent in this order density, velocity and viscosity of the mixture argon-helium-air at $x=60 \mathrm{~mm}$. As zirconia particles suspended in the plasma jet in this study have a median diameter of $0.7 \mu \mathrm{m}$, particle velocity is assumed to be equal to plasma velocity around $\mathrm{x}=60 \mathrm{~mm}[5,11,13]$. The average particle velocity value in a free jet at the centerline will be taken in this case. Symbol $\mathrm{d}_{\mathrm{s}}$ in this expression corresponds to the diameter of both substrates which is $50 \mathrm{~mm}$.

Symbol A in the third equation represents the frontal area of the substrate, of value $1964 \mathrm{~mm}^{2}$ for the flat substrate or $1600 \mathrm{~mm}^{2}$ for the cylindrical substrate. $C_{d}$ is the drag coefficient of the substrates, depending on the Reynolds number of the plasma and air mixture.

In the Stokes number definition (Eq. 4), $\rho_{\mathrm{p}}$ and $d_{\mathrm{p}}$ are respectively density and mean diameter of the submicron zirconia particles, with respective values of $5890 \mathrm{~kg} \cdot \mathrm{m}^{-3}$ and $0.7 \mu \mathrm{m}$.

Then in a similar fashion than Anderson and Longmire [22], two Stokes numbers will be computed, $\mathrm{St}_{0}$ corresponding to the particle-fluid relation at the nozzle exit of the plasma gun $\left(\mathrm{St}_{0}=\rho_{\mathrm{p}} \mathrm{d}_{\mathrm{p}}^{2} \mathrm{v}_{\mathrm{g} 0} / 18 \mu_{\mathrm{g} 0} \mathrm{D}_{0}\right)$ and $\mathrm{St}_{60}$ corresponding to the particle-fluid relation far downstream, around $60 \mathrm{~mm}\left(\mathrm{St}_{60}=\rho_{\mathrm{p}} \mathrm{d}_{\mathrm{p}}^{2} \mathrm{v}_{\mathrm{g}} / 18 \mu_{\mathrm{g}} \mathrm{D}_{0}\right)$. In the first case, the plasma velocity at nozzle exit $\mathrm{v}_{\mathrm{g} 0}$, the diameter of the nozzle $\mathrm{D}_{0}$ and the viscosity of the plasma mixture at nozzle exit $\mu_{\mathrm{g} 0}$ are taken into account (values in Tab. 1). 
Results and discussions

The aim of these measurements is to visualize the particle flow in the vicinity of the substrate surface and estimate the average value of the magnitude of particle velocity both axially, along the centerline of the plasma jet, and radially, along the plasma jet radius.

Axial evolution of particle velocity at the center of the plasma jet, comparisons between free jets and impinging jets at $x=60 \mathrm{~mm}$ from the nozzle exit

First, it is worth noting that the use of commercial cooling air-jets surrounding the gun nozzle had an impact on the plasma flow behaviour in front of the substrates. Indeed working with such cooling air flow macroscopically created an air barrier before the surface of the substrates compared to a spray with no air-jets in the same operating conditions (Fig. 4). This cold barrier had a thickness around $3 \mathrm{~mm}$ according to the corresponding velocity fields. Despite these observations, cooling air-jets were maintained to a minimum value, for every tested operating condition in order to minimise experimental variables and optimise the survival of substrates during and after each spray.

\section{Effect of the presence of a wall on the axial evolution of particle velocity}

Average particle velocities were measured at the center of the plasma jet $(y=0 \mathrm{~mm})$ between $\mathrm{x}=50 \mathrm{~mm}$ and $60 \mathrm{~mm}$ from nozzle exit. As reported in Fig. 5, velocity measurements of suspensions in a free jet showed a natural deceleration of $70 \mathrm{~m} \cdot \mathrm{s}^{-1}$ in $10 \mathrm{~mm}$, from $\mathrm{x}=50 \mathrm{~mm}$ to $60 \mathrm{~mm}$. On the other hand, free jet with surrounding air-jets showed a deceleration of about $100 \mathrm{~m} \cdot \mathrm{s}^{-1}$ on a distance of $6 \mathrm{~mm}$ from $\mathrm{x}=50.5 \mathrm{~mm}$ to $56.5 \mathrm{~mm}$. Additionally, these particles 
travel faster than the particle jet impinging a surface positioned at $\mathrm{x}=60 \mathrm{~mm}$. Indeed, a maximum gap of $200 \mathrm{~m} \cdot \mathrm{s}^{-1}$ at $53.5 \mathrm{~mm}$ from nozzle exit was registered between particles dragged in a free jet compared to particles encapsulated in a plasma jet impinging a flat substrate, with cooling air-jets in use in both cases.

Stokes numbers were computed for the submicron particle flow along the axis of the plasma jet and evolve from $0.16\left(\mathrm{St}_{0}\right)$ to $0.06\left(\mathrm{St}_{60}\right)$. In all cases, Stokes numbers are below 1. This means zirconia submicron particles are very sensitive to the plasma jet behaviour and strictly follow the plasma jet streamlines even with a decreasing plasma viscosity.

All of the above indicates the presence of a wall in front of the plasma jet disrupts greatly its dynamic behaviour which results in braking the suspension particle flow significantly upstream within the plasma jet. This braking effect is also an indirect indication of the existence of a stagnation area for the plasma flow created by the presence of a substrate. A stagnation area is a definite space where fluid particles are brought to rest due to a particular geometry of an obstacle met by the plasma flow. The dimensions of this flat substrate suffice in creating such an area.

Moreover the addition of said cooling jets has a negative effect on particle velocity. When comparing both particle flows impinging a flat substrate (Fig. 5), average velocity values drop off between $100 \mathrm{~m} \cdot \mathrm{s}^{-1}$ and $150 \mathrm{~m} \cdot \mathrm{s}^{-1}$ at respectively $50.5 \mathrm{~mm}$ and $53.5 \mathrm{~mm}$ from nozzle exit. Naturally this loss of speed depends a lot on air nozzle orientation and air flow rates. In many industrial cases implementing a rotating substrates carrier, it is then beneficial to turn off standard air-jets fixed on the gun, and cool down the substrates using others systems.

Thus, when spraying on a surface the average magnitude of particle velocity is affected by a double negative effect: the use of cooling air-jets surrounding the plasma jet and 
the presence of the surface itself which disrupts and brakes the particle flow upstream, in this case up to $10 \mathrm{~mm}$ upstream.

\section{Effect of the shape of the substrate on the axial evolution of particle velocity}

As shown in Figure 6, the average particle velocity values did not change significantly in front of the cylindrical or flat substrate geometries used in this work. Moreover, particle velocities at the center of the plasma jet decrease at the same rate in both cases. This lack of a significant difference may be the result of the small and similar cross sectional shapes of the geometries chosen. Indeed, Reynolds number of the plasma flow in front of these substrates is identical (diameter is identical for both substrates) and of magnitude $5.10^{3}$.

However, drag coefficients for these substrates at this value of Reynolds number depend on their aspect ratio according to Hoerner's experimental diagrams [23]. For the flat substrate, it is a disk of aspect ratio length/diameter of 0.56 , therefore a drag coefficient $C_{d}$ of 1.02 according to Hoerner. In the case of the cylindrical substrate the aspect ratio diameter/length was of 1.56 which corresponds to a drag coefficient $C_{d}$ tending to 0.70 . Drag forces of these substrates are then respectively of $4.9 \mathrm{~N}$ for the flat substrate and $2.7 \mathrm{~N}$ for the cylindrical substrate. Therefore, the cylindrical substrate should show slightly less resistance to the plasma flow.

The braking effect on the particle velocity produced by the substrate appears on Fig. 6 to extend less strongly upstream with a cylindrical surface than with a flat substrate, higher average velocities being registered in this former case. This trend is due to the curvature radius $(25 \mathrm{~mm})$ of the cylinder which impacts the drag force on the plasma jet and is coherent to the drag force calculation which is lower for the curved substrate. Increasing the length or reducing the curvature radius of the cylinder would likely exacerbate any differences in the 
1 particle flow kinetic behaviour in the vicinity of these two types of substrate. Moreover, the

2 curvature radius of the cylinder implies that plasma jet streamlines along the $\mathrm{z}$ axis are less

3 and less subjected to an obstacle orthogonal to their trajectories. Therefore, with this curved

4 target the stagnation zone is also weakened in size and submicron particles are less

5 decelerated by this change of plasma flow behaviour. This trend on velocity results in front of

6 a curved substrate is in agreement with simulations [13, 19].

Radial evolution of particle velocity in a free jet case or in the presence of substrates at $x=60 \mathrm{~mm}$ from nozzle exit

To further this investigation, velocities were measured along the radius of the plasma jet, which corresponds to the determination of velocity vectors along the $y$ axis. Figure 7 shows average values of magnitude of these velocity vectors at $\mathrm{x}=50.5 \mathrm{~mm}$ and $56.5 \mathrm{~mm}$ from nozzle exit.

\section{Free jet case}

As in most cases in thermal spraying, in both cross-sections, $x=50.5 \mathrm{~mm}$ and $56.5 \mathrm{~mm}$, the particle velocity radial distributions (Fig. 7) are symmetrical and show a maximum at the center of the free plasma jet. It noted that the Gaussian evolution ordinary observed for a jet is not very steepened in both cross-sections, with an average value of $315 \mathrm{~m} \cdot \mathrm{s}^{-1}$ at $50.5 \mathrm{~mm}$ and of $230 \mathrm{~m} \cdot \mathrm{s}^{-1}$ at $56.5 \mathrm{~mm}$ in a spot of $8 \mathrm{~mm}$ in diameter. 
In the case of a plasma jet impinging the flat substrate, some changes are noticed

2 compared with the kinetic behaviour in a free jet case (Fig. 7). First, at $x=50.5 \mathrm{~mm}$, every

3 velocity value along the $y$ axis is about $100 \mathrm{~m} \cdot \mathrm{s}^{-1}$ lower than velocity values registered in the

4 free jet case in the same spatial position. Secondly, the concave shape of velocities

5 distribution along the $\mathrm{y}$ axis flattens and becomes a rather convex curve at $\mathrm{x}=56.5 \mathrm{~mm}$ from

6 the nozzle exit. At $3.5 \mathrm{~mm}$ upstream of the surface of the flat substrate, the lowest velocity

7 value $74 \mathrm{~m} \cdot \mathrm{s}^{-1}$ is then at the center of the plasma jet.

These evolutions are mainly due to a maximum of static pressure in the center of the plasma jet when meeting a wall, thus due to the effect of a stagnation zone on the plasma flow. These velocity results shows that the stagnation zone is located especially in the center of the plasma jet with a decreasing intensity on static pressure along the radial axis in just a few millimetres. The plasma flow must then be deviating in a wall jet configuration in order to explain the higher velocity values of particles registered around this center.

\section{Jet impinging a cylindrical substrate}

When comparing the radial evolution of velocities between the submicron particle flow impinging a cylindrical substrate and a flat substrate (Fig. 7), the convex shape of the velocity curve already appears at $\mathrm{x}=50.5 \mathrm{~mm}$ and is preserved along the way. However, velocities are higher for a flow impinging the cylindrical substrate than a flow impinging the flat substrate, which can be easily explained by the drag forces. At $x=50.5 \mathrm{~mm}$, the particle velocity radial evolution is even almost identical in magnitude to the free jet except for the velocity value at the centerline. This shows the stagnation zone is radially narrower in size and extends less farther along the plasma flow axis with this type of substrate than with the flat substrate. The additional presence of air cooling flows may also provide an air 
acceleration around the substrate to the more peripheral particles and emphasize this curvature effect. Consequently, the flow kinetic behaviour is also less affected radially by the presence of a substrate with such a curvature $(25 \mathrm{~mm})$ than when it is impinging a flat surface.

Tilting effect of the plasma gun on particle flow kinetic behaviour near the substrate and beads morphology

\section{Tilting effect of the plasma gun particle velocity near the flat substrate}

The angle between the normal axis of the substrate surface and the gun axial axis was set at $40^{\circ}$.

Figure 8 shows two instantaneous particle velocity fields between the two cases as well as the resulting average value at $3.5 \mathrm{~mm}$ away from the substrate. This average value was obtained from the summation of all 100 velocity fields contained in a measurement window of $3 \times 3 \mathrm{~mm}^{2}$ and centered at $56.5 \mathrm{~mm}$. Respectively, an average value of $74 \mathrm{~m} \cdot \mathrm{s}^{-1}$ was measured when the plasma jet is impinging the surface in a parallel direction of the normal axis, i.e with $0^{\circ}$ of incidence to the normal axis, and $143 \mathrm{~m} \cdot \mathrm{s}^{-1}$ was registered when the gun was set at a $40^{\circ}$ angle from the substrate normal axis.

Moreover, the instantaneous particle velocity fields display that clouds of submicron particles follow the plasma jet general direction. Indeed, vectors are preserving an incident angle of approximatively $0^{\circ}$ or $40^{\circ}$ to at least $5 \mathrm{~mm}$ from the surface of the substrate. In the case of an incidence angle close to $0^{\circ}$, vectors around the centerline are starting to diverge outward and symmetrically at $5 \mathrm{~mm}$ with a gradually decreasing magnitude. When the incidence angle is $40^{\circ}$ to the normal axis, most of the vectors in the $y$ - area are diverging 


.

away from the surface of the substrate, starting $12 \mathrm{~mm}$ upstream. In the $\mathrm{y}+$ area, vectors divergence only takes place starting $5 \mathrm{~mm}$ upstream the surface with an opening angle of about $45^{\circ}$ to the substrate normal axis at $\mathrm{y}=0$. Their divergence away from the substrate surface also keeps the set direction towards the $\mathrm{y}$-. No vector was registered going against this general downward direction within the limits of the spatial dimensions of these images. The magnitude of the velocity vectors at the centerline of the plasma jet, thus diagonally on the instantaneous field (Fig. 8), also tends to decrease way less until impact compared to the impinging jet with a $0^{\circ}$ incidence, hence the overall greater average velocity value registered in this area.

Thus, enough tilt of the substrate leads to submicron particles being less decelerated upon impact although their flow direction is more affected by it as well. The orientation of the tilt leads to a preferred general direction of the submicron particle flow with the same orientation. It also means there is a less impactful stagnation zone to the plasma flow, in terms of geometrical dimensions.

\section{Beads morphology}

Next, the influence of the angle of incidence of the general submicron particle flow was studied on beads. Figure 9 displays SEM images of the beads morphologies in relation with the orientation of the plasma jet to the normal axis of the substrate.

These morphologies correlate strongly with the registered particle flow direction before the substrate. Beads produced with a gun placed orthogonally to the substrate, thus with a incidence angle close to $0^{\circ}$ at the centerline, display a homogeneous and rather dense morphology. Beads produced with a tilted plasma gun exhibit a morphology composed of columns with a strong directional growth oriented toward the center of the plasma jet. The 
angle described by the columns orientation and the normal axis of the substrate is of about $30^{\circ}$ regardless of the position in the coating from the center of the plasma jet.

The noticed difference between this column growth angle and the incidence angle of the particles impacting has been similarly reported before on columnar microstructures produced by physical vapour-phase deposition techniques, such as PS-PVD [24] and PVD [25]. These authors seem to agree that this difference is due to atomistic particles selfshadowing while the coating is growing. A similar phenomenon of particles self-shadowing could likely be happening with these submicron particles, leading to columns with an orientation towards the center of the particle flow and with a lesser angle of growth than the incidence angle of the particle flow.

Porosity at the center of the beads was also evaluated thanks to image analysis. In both beads porosity was around $20 \%$. Therefore it seems that neither impact velocity nor jet orientation at the centerline of the flow influence drastically the porosity level within the coating. Orientation of the plasma jet and impact velocities only influence the stacking of splats into columns or layers.

\section{Conclusions}

This study leads to a better understanding of coating growth by SPS thanks to the observation of the submicron particle velocity and direction in a plasma jet impinging on different types of substrate. Due to the very small particle sizes, a PIV set-up had to be used to apprehend this flow. Different substrates were then chosen: flat, curved or inclined.

It has been shown that: 
1 - The submicron particle flow consistently follows the plasma jet streamlines.

2 - The substrate presence disrupts the particle flow direction and velocity up to $10 \mathrm{~mm}$

3 upstream from the substrate surface in comparison with free jets.

4 - The positioning of air-jets is of major importance as the air flow can provoke a decrease

5 of the particle flow average velocity near the substrate.

6 - The substrate shape has an impact on the particle flow kinetic behaviour. Particles particles impinging the flat substrate.

9 - When trapped in a plasma jet impinging the flat substrate with an incidence angle of $40^{\circ}$, the particle flow keeps the plasma jet incidence at the centerline and is then less deviated plasma jet flow and particle flow in the SPS process.

However, a better characterization of the submicron particle direction and velocity upon impact is still required in order to attain a better understanding of the effect of the stagnation zone on coating growth in SPS. The next study will thus focus on better describing submicron particles kinetic behaviour very near a flat substrate in order to measure impacting velocities and their incidence angles.

\section{Acknowledgements}


2 for the financial support.

3 


\section{References}

[1] B. Bernard, A. Quet, L. Bianchi, V. Schick, A. Joulia, A. Malié, B. Rémy, Effect of Suspension Plasma-Sprayed YSZ Columnar Microstructure and Bond Coat Surface Preparation on Thermal Barrier Coating Properties, J. Therm. Spray Technol., 2017, 26(6), p 1025-1037

[2] E. Pfender, Fundamental studies associated with the plasma spray process, Surf. Coat. Technol., 1988, 34(1), p 1-14

[3] C.W. Kang, H.W. Ng, S.C.M. Yu, Comparative Study of Plasma Spray Flow Fields and Particle Behavior Near to Flat Inclined Substrates, Plasma Chem. Plasma Process., 2006, 26(2), p 149-175

[4] M. Vardelle, A. Vardelle, P. Fauchais, Spray parameters and particle behavior relationships during plasma spraying, J. Therm. Spray Technol., 1993, 2(1), p 79-91

[5] J.O. Berghaus, S. Bouaricha, J.G. Legoux, C. Moreau, Injection conditions and in-flight particle states in suspension plasma spraying of alumina and zirconia nano-ceramics, Thermal Spray 2005: Thermal Spray Connects: Explore Its Surfacing Potential!, E. Lugscheider, Ed., May 2-4, 2005 (Basel, Switzerland), DVS-German Welding Society, 2005, p $2-4$

[6] R. Etchart-Salas, V. Rat, J.F. Coudert, P. Fauchais, N. Caron, K. Wittman, S. Alexandre, Influence of Plasma Instabilities in Ceramic Suspension Plasma Spraying, J. Therm. Spray Technol., 2007, 16(5-6), p 857-865

[7] C. Delbos, J. Fazilleau, V. Rat, J.F. Coudert, P. Fauchais, B. Pateyron, Phenomena Involved in Suspension Plasma Spraying Part 2: Zirconia Particle Treatment and Coating Formation, Plasma Chem. Plasma Process., 2006, 26(4), p 393-414

[8] H. Martin, Heat and Mass Transfer between Impinging Gas Jets and Solid Surfaces, Adv. Heat Transfer, 1977, 13, p 1-60 
1 [9] C.G. Phillips, S.R. Kaye, The Influence of The Viscous Boundary Layer on The Critical

Stokes Number for Particle Impaction Near A Stagnation Point, J. Aerosol Sci., 1999, 30(6), p 709-718

[10] P. Fauchais, R. Etchart-Salas, V. Rat, J.F. Coudert, N. Caron, K. Wittmann-Ténèze, Parameters Controlling Liquid Plasma Spraying: Solutions, Sols, or Suspensions, J. Therm. Spray Technol., 2008, 17(1), p 31-59

[11] M. Jadidi, M. Mousavi, S. Moghtadernejad, A. Dolatabadi, A Three-Dimensional Analysis of the Suspension Plasma Spray Impinging on a Flat Substrate, J. Therm. Spray Technol., 2015, 24(1-2), p 11-23

[12] A. Farrokhpanah, T.W. Coyle, J. Mostaghimi, Numerical Study of Suspension Plasma Spraying, J. Therm. Spray Technol., 2017, 26(1-2), p 12-36

[13] K. Pourang, C. Moreau, A. Dolatabadi, Effect of Substrate and Its Shape on in-Flight Particle Characteristics in Suspension Plasma Spraying, J. Therm. Spray Technol., 2016, 25(1-2), p 44-54

[14] K. VanEvery, M.J.M. Krane, R.W. Trice, H. Wang, W. Porter, M. Besser, D. Sordelet, J. Ilavsky, J. Almer, Column Formation in Suspension Plasma-Sprayed Coatings and Resultant Thermal Properties, J. Therm. Spray Technol., 2011, 20(4), p 817-828

[15] P. Sokołowski, S. Kozerski, L. Pawłowski, A. Ambroziak, The key process parameters influencing formation of columnar microstructure in suspension plasma sprayed zirconia coatings, Surf. Coat. Technol., 2014, 260, p 97-106

[16] E. Aubignat, M.P. Planche, D. Billieres, A. Allimant, L. Girardot, Y. Bailly, G. Montavon, Optimization of the injection with a twin-fluid atomizer for suspension plasma spray process using three non-intrusive diagnostic tools, J. Visualization, 2016, 19(1), p $21-36$ 
1 [17] B. Bernard, L. Bianchi, A. Malié, A. Joulia, B. Rémy, Columnar suspension plasma sprayed coating microstructural control for thermal barrier coating application, J. Eur. Ceram. Soc., 2016, 36(4), p 1081-1089

[18] Y. Zhao, Z. Yu, M.-P. Planche, A. Lasalle, A. Allimant, G. Montavon, H. Liao, Influence of Substrate Properties on the Formation of Suspension Plasma Sprayed Coatings, $J$. Therm. Spray Technol., 2018, 27(1-2), p 73-83

[19] T. Ba, C.W. Kang, H.W. Ng, Numerical Study of the Plasma Flow Field and Particle Inflight Behavior with the Obstruction of a Curved Substrate, J. Therm. Spray Technol., 2009, 18:858, doi:10.1007/s11666-009-9395-1

[20] S. Bansard, "Etude de l'ablation d'un composite -fibres de carbone, résine phénoliquepar impact de gouttes d'alumine : Conception d'un banc d'expériences", Ph.D. Thesis, University of Limoges, 2004

[21] H.X. Wang, X. Chen, W. Pan, Modeling Study on the Entrainment of Ambient Air into Subsonic Laminar and Turbulent Argon Plasma Jets, Plasma Chem. Plasma Process., 2007, 27(2), p 141-162

[22] S.L. Anderson and E.K. Longmire, Particle Motion in the Stagnation Zone of an Impinging Air Jet, J. Fluid Mech., 1995, 299, p 333-366

[23] S.F. Hoerner, Fluid-dynamic drag: theoretical, experimental and statistical information, L.A. Hoerner, ～Ed., Hoerner Fluid Dynamics, 1992, Chap. 3

[24] P. Wang, W. He, G. Mauer, R. Mücke, R. Vaßen, Monte Carlo simulation of column growth in plasma spray physical vapor deposition process, Surf. Coat. Technol., 2018, 335, p 188-197

[25] A.G. Dirks, H.J. Leamy, Columnar microstructure in vapor-deposited thin films, Thin Solid Films, 1977, 47(3), p 219-233 
1 Fig. 1 Diagram of the PIV set-up used in this study

2 Fig. 2 Diagram representing the spraying distance and substrates in use

3 Fig. 3 Photography of a spray during PIV measurements done in presence of a rotating

$4 \quad$ stainless steel ring and cooling air-jets

5 Fig. 4 Photography of two spray in front of a stainless steel ring with air-jets off or air-jets on

6 Fig. 5 Evolution at the centerline of the plasma flow of particle average velocity magnitudes

$7 \quad|\mathrm{v}|$ with or without cooling air-jets or with or without the substrate presence at $\mathrm{x}=60 \mathrm{~mm}$ from

8 plasma gun nozzle exit

9 Fig. 6 Average of particle velocity magnitudes at the plasma jet centerline when impinging cylindrical and flat substrates positioned at $\mathrm{x}=60 \mathrm{~mm}$ and with the use of air-jets

Fig. 7 Radial evolution of the average of magnitudes of particle velocities at $x=50.5 \mathrm{~mm}$ or $\mathrm{x}=56.5 \mathrm{~mm}$ from nozzle exit, in the case of a free plasma jet and in the presence of a cylindrical or flat substrate situated at $\mathrm{x}=60 \mathrm{~mm}$

Fig. 8 Tilting effect of the plasma gun on particle velocity at $3.5 \mathrm{~mm}$ from the flat substrate (window of measurement represented by the dotted rectangle) and on instantaneous particle velocity fields. Green arrows help to illustrate velocity vector directions \& magnitudes represented by smaller red arrows. The white clouds are puff of zirconia particles impinging the surface

Fig. 9 SEM images of beads obtained on rotating cylinders with a $0^{\circ}$ (a) or $40^{\circ}$ angle of incidence of the plasma jet (b) to the substrate normal axis. A sketch in (b) also displays the angle of columns to the substrate normal axis 
Table 1 Spraying conditions

\begin{tabular}{|l|l|}
\hline Gas mixture Ar/He & $80 \% / 20 \%$ \\
\hline Total gas flow rate & $50 \mathrm{~L} \cdot \mathrm{min}^{-1}$ \\
\hline Nozzle diameter $D_{0}$ & $6.5 \mathrm{~mm}$ \\
\hline Electric power & $23.5 \mathrm{~kW}$ \\
\hline Plasma jet mass enthalpy & $22.2 \mathrm{MJ} \cdot \mathrm{kg}^{-1}$ \\
\hline Plasma jet temperature (at nozzle exit, estimated from mass enthalpy) & $13400 \mathrm{~K}$ \\
\hline Plasma jet velocity $v_{\mathrm{g} 0}$ (calculated average at nozzle exit) & $1450 \mathrm{~m} \cdot \mathrm{s}^{-1}$ \\
\hline Plasma jet viscosity $\mu_{\mathrm{g} 0}($ estimated from mass enthalpy) & $2.30 \cdot 10^{-4} \mathrm{~kg} \cdot \mathrm{m}^{-1} \cdot \mathrm{s}^{-1}$ \\
\hline Stand-off distance & $60 \mathrm{~mm}$ \\
\hline Injector diameter & $150 \mu \mathrm{m}$ \\
\hline Suspension flow rate & $30 \mathrm{~mL} \cdot \mathrm{min}^{-1}$ \\
\hline Air-jets flow rate & $15 \mathrm{~m}^{3} \cdot \mathrm{h}^{-1}$ \\
\hline Chuck rotation speed & $100 \mathrm{rpm}$ \\
\hline
\end{tabular}

2 